\title{
Drying kinetics; a comparison of diffusion coefficients from moisture concentration profiles and drying curves
}

\section{Citation for published version (APA):}

Ketelaars, A. A. J., Pel, L., Coumans, W. J., \& Kerkhof, P. J. A. M. (1995). Drying kinetics; a comparison of diffusion coefficients from moisture concentration profiles and drying curves. Chemical Engineering Science, 50(7), 1187-1191. https://doi.org/10.1016/0009-2509\%2894\%2900494-C, https://doi.org/10.1016/00092509(94)00494-C

\section{DOI:}

10.1016/0009-2509\%2894\%2900494-C

10.1016/0009-2509(94)00494-C

Document status and date:

Published: 01/01/1995

\section{Document Version:}

Publisher's PDF, also known as Version of Record (includes final page, issue and volume numbers)

\section{Please check the document version of this publication:}

- A submitted manuscript is the version of the article upon submission and before peer-review. There can be important differences between the submitted version and the official published version of record. People interested in the research are advised to contact the author for the final version of the publication, or visit the $\mathrm{DOI}$ to the publisher's website.

- The final author version and the galley proof are versions of the publication after peer review.

- The final published version features the final layout of the paper including the volume, issue and page numbers.

Link to publication

\section{General rights}

Copyright and moral rights for the publications made accessible in the public portal are retained by the authors and/or other copyright owners and it is a condition of accessing publications that users recognise and abide by the legal requirements associated with these rights.

- Users may download and print one copy of any publication from the public portal for the purpose of private study or research.

- You may not further distribute the material or use it for any profit-making activity or commercial gain

- You may freely distribute the URL identifying the publication in the public portal.

If the publication is distributed under the terms of Article 25fa of the Dutch Copyright Act, indicated by the "Taverne" license above, please follow below link for the End User Agreement:

www.tue.nl/taverne

Take down policy

If you believe that this document breaches copyright please contact us at:

openaccess@tue.nl

providing details and we will investigate your claim. 


\title{
DRYING KINETICS: A COMPARISON OF DIFFUSION COEFFICIENTS FROM MOISTURE CONCENTRATION PROFILES AND DRYING CURVES
}

\author{
A. A. J. KETELAARS, ${ }^{\dagger}$ L. PEL, ${ }^{\ddagger}$ W. J. COUMANS ${ }^{\dagger}$ and P. J. A. M. KERKHOF ${ }^{\dagger}$ \\ ${ }^{\dagger}$ Department of Chemical Engineering (TCP), and ${ }^{\ddagger}$ Department of Architecture and Building Technology \\ (FAGO), Eindhoven University of Technology, P.O. Box 513, 5600 MB Eindhoven, The Netherlands
}

(Received 1 August 1993; accepted in revised form for publication 14 October 1994)

\begin{abstract}
The mathematical formulation of mass transfer in drying processes is often based on the diffusion equation. In principle the diffusion coefficient as a function of moisture content has to be determined experimentally. The most direct approach is to derive the diffusion coefficient from experimental moisture concentration profiles in the material during drying. In this work, the diffusion coefficient determined in this way is called the actual diffusion coefficient. Very often, however, an indirect method is used based on drying curves (average moisture content of a sample vs time). Since the diffusion coefficient is determined indirectly from the macroscopic behaviour of the sample, this coefficient will be called the apparent diffusion coefficient. A comparison of diffusion coefficients as a function of moisture content using both methods shows that for porous materials such as clays, the apparent diffusion coefficient depends on experimental conditions. This can be explained by the fact that the apparent diffusion coefficient is in agreement with the actual diffusion coefficient over a limited range of moisture content only. For materials such as clays, drying curves are not suited to derive diffusion coefficients as a function of moisture content in a satisfactory and consistent way.
\end{abstract}

\section{INTRODUCTION}

The mathematical formulation of mass transfer in porous media during drying is usually based on a diffusion equation [e.g. Philip and de Vries (1957)]. A more fundamental basis for this equation was later given by Bear (1990) and Whitaker (1977). The diffusion coefficient is an overall coefficient describing the moisture flow by liquid, vapour and combined liquid/vapour transport. In principle the diffusion coefficient, which is both temperature and moisture concentration dependent, has to be determined experimentally. In many cases in literature the moisture concentration dependency of the (isothermal) diffusion coefficient is derived from drying curves [e.g. Coumans (1987) and Collard et al. (1992)]. The experimental conditions are chosen such that a numerical solution of the diffusion equation can be obtained (e.g. one-dimensional drying of a slab). The diffusion coefficient as a function of moisture content is varied until a best fit is obtained.

The most important drawback of using drying curves is that a functional relation has to be chosen for the diffusion coefficient as a function of moisture content, e.g. an exponential relation $\left(D=D_{0} e^{a \theta}\right)$. In principle, however, it is not known what kind of relation is appropriate. As a matter of fact, obtaining this information was the purpose of doing the drying experiment in the first place. For this reason this diffusion coefficient will be called the apparent diffusion coefficient in this paper.

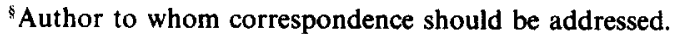

For determining the diffusion coefficient as a function of moisture content without having to assume a functional relation, the experimental determination of moisture concentration profiles as a function of time is necessary. Recently, it has been shown by the authors that scanning neutron transmission can be used for the purpose of obtaining profiles with sufficient accuracy in materials such as brick and clay (Ketelaars, 1992; Pel et al., 1992). A diffusion coefficient can be determined from these profiles directly and therefore will be called the actual diffusion coefficient in this paper.

Using scanning neutron radiography to obtain moisture concentration profiles, however, has some disadvantages. A nuclear facility should be available to produce neutron beams of sufficiently high intensity, specially trained personnel are necessary, safety precautions are strict and the method is rather expensive. Furthermore, the method is restricted to materials which do not contain much hydrogen such as, e.g., ceramics. These disadvantages are such that a wide application of this experimental method is not to be expected and in many practical situations only drying curves will be available for the determination of the diffusion coefficient. An interesting question therefore is whether or not the apparent diffusion coefficient is in agreement with the actual one.

\section{THE ACTUAL DIFFUSION COEFFICIENT FROM MOISTURE CONCENTRATION PROFILES}

\subsection{Principle}

Neutrons interact with nuclei. When a beam of neutrons passes through a material, the attenuation of 
this beam will depend on the type and amount of nuclei present. The attenuation of a neutron beam of intensity $I_{0}$ by a material containing $i$ components, is given by

$$
I=I_{0} e^{-\sum_{i} d_{i} \mu_{i}}
$$

in which $\mu_{i}$ is a macroscopic attenuation coefficient for component $i$ (expressed per meter of $i$ ) and $d_{i}$ is a so-called equivalent thickness for this component. For a rigid non-shrinking material with a volumetric moisture content $\theta$ and thickness $d$, eq. (1) reduces to

$$
I=I_{0} e^{-d\left(\mu_{\mathrm{mat}}+\theta \mu_{w}\right)} \text {. }
$$

The macroscopic attenuation coefficients $\mu_{w}$ and $\mu_{\text {mat }}$ can be determined experimentally by measuring the transmission of pure water and dry material, respectively. Once these values are known, moisture content can be determined by measuring the transmission of a sample of given thickness $d$. For many materials $\mu_{w} \gg \mu_{\text {mat }}$, which makes the method very accurate. For a detailed description of experimental set-up and validation of the method the reader is referred to literature (Ketelaars, 1992; Pel et al., 1992).

\subsection{Experimental results}

Moisture concentration profiles were measured during drying of a non-shrinking kaolin clay. This kaolin clay (Kaolins d'Arvor, France) was chosen because of its purity and well-defined properties such as pore and particle size distribution. From this material reproducible samples could be prepared. Measuring the moisture content at a single point with an accuracy of $1 \%$ takes about $40 \mathrm{~s}$ and an entire profile consisting of 28 data points takes $20 \mathrm{~min}$. Since high gradients in moisture content are expected to occur near the drying surface, a variable grid was used for scanning, ranging from $0.5 \mathrm{~mm}$ when the beam is near the drying surface to $2 \mathrm{~mm}$ at the bottom of the sample. Drying experiments last up to $24 \mathrm{~h}$. The moisture concentration profile at a specific time is deduced from the experimental data by an interpolation of the moisture concentration as a function of time for every data point. Temperature profiles were measured during the experiments (Pel et al., 1992). Apart from the first hour in which temperature profiles develop, the experiments can be considered isothermal. An example of the evolution of the moisture concentration profile as a function of time is given in Fig. 1. In this example some minor inhomogeneities can be seen near the drying surface $(x=0.027 \mathrm{~m})$ which are most likely due to sample preparation. At the bottom of the sample $(x=0 \mathrm{~m})$ evaporation is prevented, so according to theory no moisture concentration gradient should be present in the material at this point. In Fig. 1 it is shown experimentally that this condition is satisfied.

\subsection{The actual diffusion coefficient}

The diffusion equation for non-shrinking systems and for a one-dimensional isothermal situation as encountered during the neutron radiography

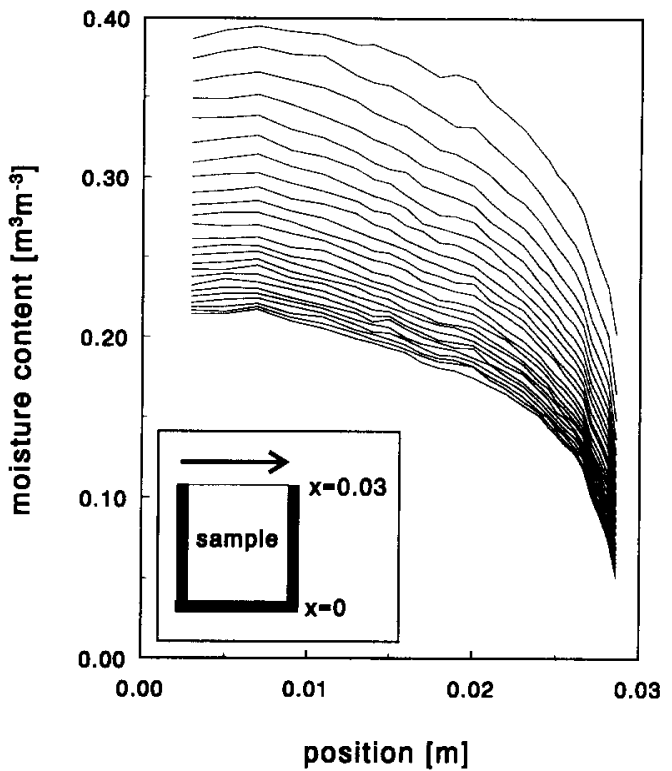

Fig. 1. Moisture concentration profiles measured during drying for a kaolin clay. Sample height $=2.95 \mathrm{~cm}, T=21^{\circ} \mathrm{C}$. Time interval between subsequent profiles is $1460 \mathrm{~s}$, first profile at $2182 \mathrm{~s}$, total drying time is $11 \mathrm{~h}$. In the inset of the figure the experimental set-up is illustrated.

measurements reads:

$$
\frac{\partial \theta}{\partial t}=\frac{\partial}{\partial x}\left(D_{\theta} \frac{\partial \theta}{\partial x}\right)
$$

in which $\theta$ is the volume fraction of moisture. To derive the diffusion coefficient from measured moisture concentration profiles this equation is integrated with respect to $x$, yielding

$$
D_{\theta}=\frac{\int_{0}^{x} \frac{\partial \theta}{\partial t} \mathrm{~d} \xi}{\left.\frac{\partial \theta}{\partial \xi}\right|_{x}} .
$$

In this equation use is made of the fact that the derivative of $\theta$ with $x$ is zero at the vapour tight bottom. Equation (4) can be applied to every data point and, since moisture content is also known for every point, the diffusion coefficient can be related to moisture content directly. The results for a kaolin clay, see Fig. 2, were obtained from various experiments on samples of the same type of material with varying initial moisture content under identical experimental conditions. The behaviour shown in Fig. 2 is characteristic for porous materials. The minimum is related to the occurrence of a receding drying front at low moisture content when the contribution of vapour diffusion in the total moisture flux becomes dominant [see e.g. Lartigue et al. (1989), Pel et al. (1992) and Ketelaars, (1992)]. The data in this figure have a scatter which is directly related to the accuracy with which the derivative of the moisture content with respect to position can be determined. However, the 


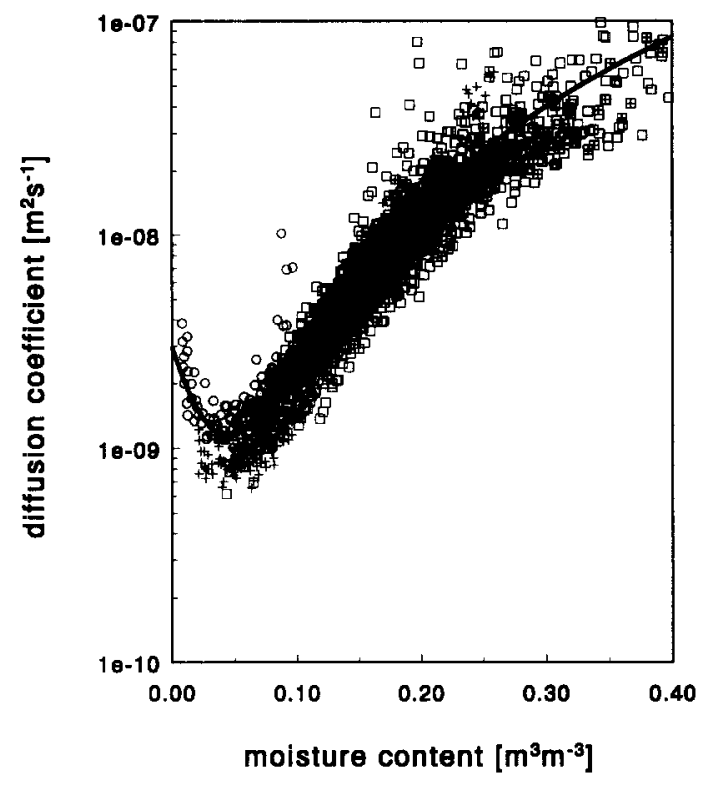

Fig. 2. Isothermal actual diffusion coefficient determined from measured moisture concentration profiles for a kaolin clay. This figure contains approximately 2000 points and is based on several experiments. (- indicates the diffusion coefficient as used in simulations.

data from the various experiments reveal a welldefined variation of the diffusion coefficient with moisture content.

\section{THE APPARENT DIFFUSION COEFFICIENT DETERMINED FROM DRYING CURVES}

The method used most frequently in literature to obtain diffusion coefficients is based on drying curves (average moisture content vs time). For the materials considered here these drying curves were also determined. Since this is a rather standard (but by no means simple!) experimental procedure it will not be discussed here in much detail.

Drying curves are obtained using the experimental set-up described elsewhere (Coumans, 1987), see Fig. 3. In this apparatus a slab of material is isothermally dried from the top surface. From the weight loss of the sample a drying curve, average moisture content vs time, was obtained. Various isothermal experiments have been performed on slabs 4 and $25 \mathrm{~mm}$ in thickness. A best fit of the numerical solution of the diffusion, eq. (3), has been obtained using an exponential relation for the diffusion coefficient as a function of moisture content $\left(D=D_{0} e^{a \theta}\right)$. A convective boundary condition at the free surface has been used, based on the desorption isotherm which was determined independently (Ketelaars, 1992). The results for 4 typical experiments are reported in Table 1.

The values for the parameters $\left(a, D_{0}\right)$ vary considerably for the various experiments. This is also seen with other samples (Ketelaars, 1992). Since the apparent diffusion coefficient is dependent on experimental
Table 1. Results of the minimization procedure for a kaolin clay

\begin{tabular}{|c|c|c|c|c|}
\hline & \multirow{2}{*}{$\begin{array}{c}\text { Initial } \\
\text { moisture } \\
\text { content } \\
\mathrm{m}^{3} \mathrm{~m}^{-3}\end{array}$} & \multirow{2}{*}{$\begin{array}{c}\text { slab } \\
\text { thickness } \\
\text { mm }\end{array}$} & \multicolumn{2}{|c|}{$\begin{array}{l}\text { Parameters in } \\
\text { exponential } \\
\text { relation }\end{array}$} \\
\hline & & & $a$ & $D_{0}$ \\
\hline 1 & 0.40 & 4 & 3.1 & $1.6 \times 10^{-9}$ \\
\hline 2 & 0.40 & 4 & 4.3 & $1.1 \times 10^{-9}$ \\
\hline 3 & 0.37 & 25 & 17 & $5.7 \times 10$ \\
\hline 4 & 0.29 & 25 & 18 & $4.2 \times 10$ \\
\hline
\end{tabular}

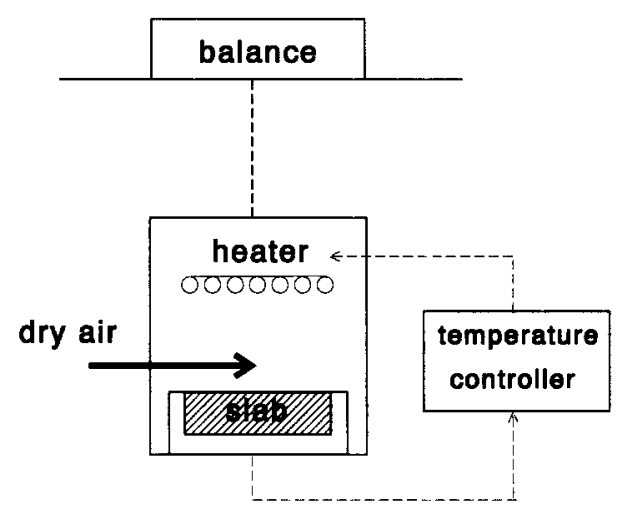

Fig. 3. Apparatus used for experimental determination of the drying curve.

conditions one could conclude that the diffusion model is incorrect or incomplete. It will be shown in the next section, however, that this is not the case.

\section{COMPARISON OF THE ACTUAL AND APPARENT DIFFUSION COEFFICIENT}

The results for the diffusion coefficient as a function of moisture content as found according to both methods are combined in Fig. 4. The apparent diffusion coefficient coincides with the actual one over a limited range of moisture content only. For thin slabs this agreement is in the low moisture content range, whereas for thick slabs this is in the intermediate moisture content range.

In order to explain this behaviour, drying curves for thick and thin slabs are given in Fig. 5. For a thin slab there is a considerable externally limited period in the beginning of the experiment. For this period the fit of the average moisture content vs time is not sensitive to the moisture content distribution in the sample. In the region for low-average moisture content there is an internally limited, the so-called falling drying rate, period. In this region the fit is sensitive to the moisture concentration distribution in the sample. However, due to the fact that an exponential relation is used only an "averaged" value is obtained.

From the drying curves it is not possible to determine over which moisture content range this coefficient is averaged. This is shown from the drying curve 


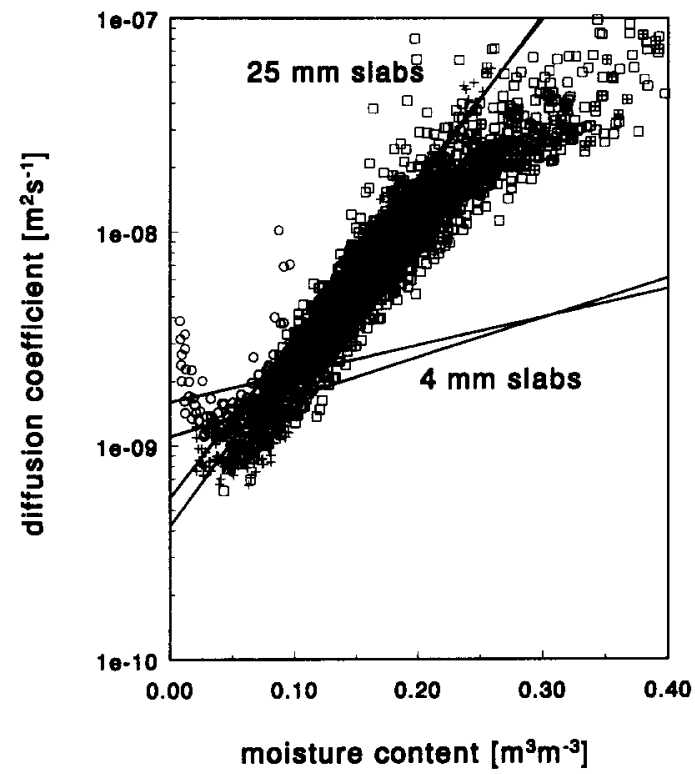

Fig. 4. Diffusion coefficient plotted against the corresponding moisture content for a kaolin clay. Data points derived from experimental moisture concentration profiles (actual diffusion coefficient), lines derived from drying curves (apparent diffusion coefficient).

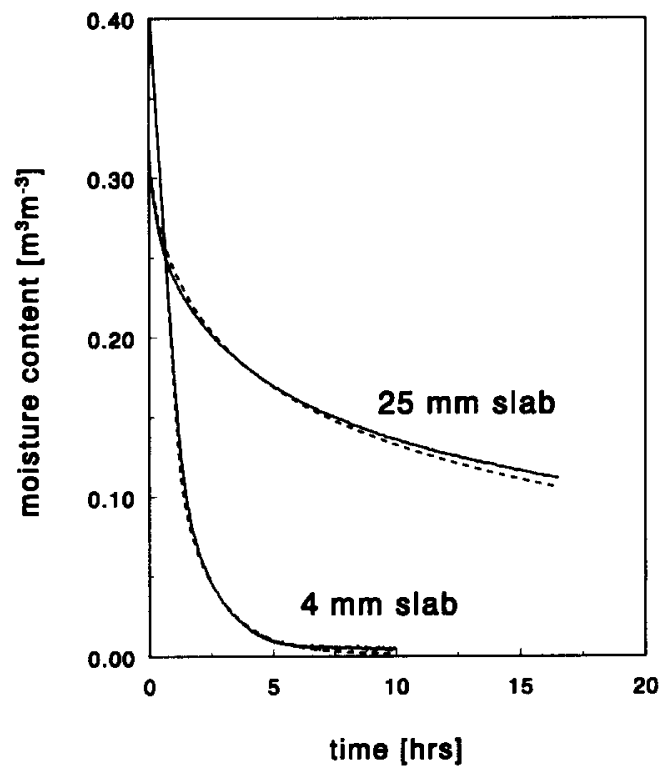

Fig. 5. Drying experiments for thin and thick slabs of kaolin clay. Experimental (-) and simulated (- - ) drying curves using the actual diffusion coefficient as a function of moisture content (see Fig. 2).

for the thick sample. For this drying curve the sample is in the internally limited period completely. Since the average moisture content is still quite high this means that substantial profiles have developed. Even though low moisture contents are present in the sample, the agreement of actual and apparent diffu- sion coefficient is in the intermediate moisture content range. The apparent diffusion coefficient seems to be an "averaged" actual diffusion coefficient, whereas it is not possible to tell which averaging procedure is involved. Unfortunately this implies that the use of drying curves in order to determine a diffusion coefficient as a function of moisture content is rather limited.

In Fig. 2 a relation for the actual diffusion coefficient as a function of moisture content is constructed from the experimental data. It is shown in Fig. 5 that with this relationship for the actual diffusion coefficient, drying curves for both thin and thick slabs can be described very well. This emphasizes the fact that it is not an improper or incomplete diffusion model which is causing the variation in the apparent diffusion coefficient.

\section{CONCLUSIONS}

It has been shown that the use of drying curves in order to obtain the diffusion coefficient as a function of moisture content does not give satisfactory results for porous materials such as clays. The diffusion coefficient derived from drying curves is only an apparent coefficient. The apparent diffusion coefficient derived from drying experiments under specific conditions can not be used to predict drying curves for other experimental conditions.

To derive a proper and reliable diffusion coefficient an experimental determination of transient moisture concentration profiles is necessary. This actual diffusion coefficient can be used in order to perform reliable predictions of drying behaviour.

Acknowledgements - The authors are very indebted to A. A. van Well and P. v. d. Ende of the Interfacultair Reactor Instituut, Delft University of Technology for their assistance during experiments with the neutron transmission technique. This project was financially supported by The Netherlands Agency for Energy and the Environment (NOVEM) and the Royal Association of Dutch Brick Manufacturers (KNB).

\begin{tabular}{ll} 
& \multicolumn{1}{c}{ NOTATION } \\
$a$ & constant \\
$d$ & equivalent thickness, $\mathrm{m}$ \\
$D_{\theta}$ & isothermal diffusion coefficient, $\mathrm{m}^{2} \mathrm{~s}^{-1}$ \\
$I$ & intensity of neutron beam, $\mathrm{s}^{-1}$ \\
$t$ & time, $\mathrm{s}$ \\
$x$ & place coordinate, $\mathrm{m}$
\end{tabular}

Greek letters

$\theta \quad$ volumetric moisture content $\left(\mathrm{m}^{3}\right.$ water) $\left(\mathrm{m}^{3} \text { total }\right)^{-1}$

$\mu \quad$ macroscopic attenuation coefficient, $\mathrm{m}^{-1}$

$\xi \quad$ local place coordinate, $\mathrm{m}$

Superscripts and subscripts

w water

0 initial

mat material 


\section{REFERENCES}

Bear, J. and Bachmat, Y., 1990, Introduction to Modeling of Transport Phenomena in Porous media, Vol. 4. Kluwer, Dordrecht.

Collard, J. M., Arnaud, G., Fohr, J. P. and Dragon, A., 1992 The drying and straining of a clay plate. Int. J. Heat Mass Transfer 35, 1103-1115.

Coumans, W. J., 1987, Power law diffusion in drying processes. Ph.D. thesis, Eindhoven University of Technology.

Ketelaars, A. A. J., 1992, Drying deformable media, Kinetics, shrinkage and stresses. Ph.D. thesis, Eindhoven University of Technology.
Lartigue, C., Puiggali, J. R. and Quintard, M., 1989, A simplified study of moisture transport and shrinkage in wood, in Drying ' 89 Edited by A. S. Majumdar and M. A. Roques, pp. 169-179. Hemisphere, Washington, DC.

Pel, L., Ketelaars, A. A. J., Adan, O. C. G. and van Well, A. A., 1993, Determination of moisture diffusivity in porous media using scanning neutron radiography. Int. $J$. Heat Mass Transfer 36, 1261-1267.

Philip, J. R. and de Vries, D. A., 1957, Moisture movement in porous materials under temperature gradients. Trans. Am. Geophys. Un. 38, 222-232.

S. Withaker, 1977, Simultaneous heat, mass and momentum transfer in porous media. A theory of drying porous media. Adv. Heat Transfer 13, 119-200. 